\title{
Beyond Silos: Complex Global Shocks and the New Challenges for Civil Society
}

\author{
Naomi Hossain*
}

\begin{abstract}
Events since 2008 have crystallised a view that global economic shocks are more likely, more complex and more contagious than in the past. Public sector spending (including aid) has been shrinking since the economic crisis, while poverty and inequality have risen in both developed and developing countries. Yet the space for new understandings of how the world economy does - and should - work, remains empty, and emerging institutions of global governance are undemocratic and non-participative. Drawing on debates taking place within civil society in the aftermath of the crisis, this article identifies the need to reimagine the way civil society works in this changed and challenging context: the challenges include moving beyond organisational 'silos' to address cross-cutting issues at their source, to amplify the voice of those directly affected, influence a fairer policy response and fertilise debate about how the global economy should work, and for whom.
\end{abstract}

\section{How the new global risk context is setting new challenges for civil society}

Events surrounding the global financial crash of 2008 have crystallised a view that the speed with which economic shocks are transmitted around the world has accelerated; that the shocks are increasingly complex in nature; and that they are not going away any time soon (Evans et al. 2010)! It has been a topsy-turvy kind of crisis: poorer countries have demonstrated more macroeconomic resilience than richer countries, leading some to view it as a rich country crisis; financial meltdown has dominated the headlines, yet millions of people have been hit far harder by the relatively silent crisis of food and fuel inflation (Tiwari and Zaman 2010); the financial sector has recovered globally, as evidenced by the recovery in bankers' bonuses, yet the public sector, which financed its recovery, looks set for a protracted period of downturn.

Three years after the collapse of Lehman Brothers, the global economy still looks vulnerable - the result of the sovereign debt crisis in the Eurozone, the fragile recovery elsewhere and the uncertainty generated by the Arab Spring and widespread social unrest. In terms of how people's lives and wellbeing have been affected, evidence is still only beginning to emerge (Global Pulse 2010). But for many people who lived in poverty before the crises struck, whether in developed or developing countries, the second half of the 'noughties' were tough. There is evidence that this was a period of belt-tightening, rising and volatile prices of essentials, stress, uncertainty, overwork and deeper impoverishment.

For some people, and not only the global intelligentsia and opinion formers, this was a moment of potential, in which there was a global re-evaluation of the practices and values that underpinned both the flourishing and the collapse of the global financial system. This article was written in part, as a contribution to an international discussion about the role of civil society at such a time, as part of the CIVICUS conference in $2010 .{ }^{1}$ Yet it is not clear to what extent such a re-evaluation has, in fact, taken place. For those of us who think of ourselves as progressive, leftist, liberal, radical, pro-poor, pro-social justice or in other ways oriented towards a more equitable and democratic world system, the moment seems to have slipped through our fingers. 
Within development, if the crises prised open any spaces in which to rethink the rules and systems that govern the world economy, these seem to have been quickly closed down. ${ }^{2}$ In social protection, poverty reduction and related policy areas, there was much talk early on of 'crisis as an opportunity', to encourage national governments to invest in establishing the social protection systems that are so plainly needed. There are few signs that this has happened so far; if anything, the rising cost of essentials has widened the gap between basic needs and social provisioning (McCord 2010). The fiscal space afforded by aid flows is narrowing, as rich countries feel less generous in a more austere era of deficit consolidation. If the intellectual or activist left have come up with new ideas, or theories, or ways of explaining the world at a time of global economic meltdown, they and their supporters have been very quiet about it. What looked like a golden opportunity to advance new, people-centred, egalitarian and empowering ideas about how to run the world has, it seems, been squandered.

At the same time, we have become increasingly aware of the significance of global governance in setting and policing the regulatory framework for the global economy. Yet, as one scholar of civil society and global governance has noted, the G20 and the related institutions of global governance that have come to the fore in the last two years are non-participative organisations, in which faceless 'sherpas' and finance ministry officials take critical national policy decisions with global policy consequences behind closed doors (Scholte 2010).

To summarise, we are in a period of:

- shrinking public sector spending in rich and aid donor countries;

- growing need among the poor in both developed and developing countries, in contexts of low economic growth and declining public social spending;

- an unfilled space for new understandings of how the world economy does - or should work, and

- rising concerns about the undemocratic and non-participative nature of emerging institutions of global governance.

There is clearly room here for civil society to act. But what new challenges do these new understandings of the rising risk of global economic shocks pose for civil society? The purpose of this brief article is to explore some of these challenges in an effort to support thinking about the civil society response.

\section{How have recent global economic shocks affected people's lives and wellbeing?}

To make sense of the new challenges facing civil society, I turn to some recent first-hand evidence about how people have been experiencing these shocks; this is particularly crucial as a corrective against any possible complacency that poor people have somehow been shielded from these shocks. ${ }^{3}$ From that evidence, three main findings of relevance to the civil society response are extracted: (1) that the longer-term effects on poverty, inequality and ill-being of these shocks are likely to have been underestimated;

(2) official and non-state sources of support were generally inadequate in developing countries and (3) few people appeared to have more than a basic grasp of the global nature of the problems they were facing in their everyday lives.

The evidence for these claims is from research conducted with people living in poverty in 15 communities in eight countries (Bangladesh, England, Indonesia, Jamaica, Kenya, Northern Ireland, Yemen and Zambia) between 2009 and 2011. The research approach was participatory and qualitative, working with rural and urban communities in each country, and involving three years of repeat visits in Bangladesh, Indonesia, Kenya and Zambia. The 2009 and 2010 developing country research was funded by the UK Department for International Development (DFID); the UK research was funded by the Joseph Rowntree Foundation and the 2011 research was funded by Oxfam GB. Partner organisations in each country led the research, with support from IDS. ${ }^{4}$

\subsection{Complex, concealed effects}

A key finding of the research across these varied contexts was that many of the most serious effects were likely to be underestimated. There were several reasons for this:

Across the communities, it was found that poor people's lives and wellbeing were being affected in ways that were not observed or measured through standard economic indicators. These included raised levels of 
stress and domestic tensions around, for example excessive drinking by men; harder unpaid care work, and for longer hours, as women spent more time and effort searching for free or cheap vegetables or fuel; less highquality and diverse diets; more uncertainty around jobs and incomes, particularly as the informal sector became increasingly crowded with entrants from formal sector jobs hit by the global downturn, and more women entering petty trading and other services to help meet the rising costs of feeding a family.

- While the global financial crisis dominated headlines and policymakers' attention, people were more widely and more directly affected by food and fuel price volatility. This was true even in the UK, where the financial crisis and accompanying downturn struck far harder than in the developing countries studied as part of the research.

The transmission channels and local outcomes of global crises were extremely complex. In most contexts, the global economic shocks were compounded locally by adverse climate and political conditions (drought in Kenya, Jamaica, Yemen; localised flooding in Indonesia; cyclone and floods in Bangladesh; heavy rains in Zambia; post-election violence in Kenya; a caretaker interregnum in Bangladesh; war and security concerns in Yemen (this was in 2010, almost a year before the uprising that took place during the 2011 Arab Spring). Compound, complex crises were interacting with each other, making it difficult to disentangle their impacts on people's lives.

- In the aftermath of the financial crisis, there were signs of rising inequality. More powerful groups (firms, and to some extent, public sector and formal sector workers) appeared to have benefited from tax breaks, more 'flexible' employment regulations and collective wage rises. By contrast, less powerful groups, such as informal sector workers, small farmers and manual labourers were struggling with stagnant wages at a time of rising food and fuel prices.

\subsection{Sources of support in times of crisis: society, civil society and the state}

The localised accounts of crisis offered some insights into how the food, fuel and financial crises unfolded in developing and developed countries. The situation was different everywhere, but everywhere there were signs of strain. Many people were trying hard to adapt but many people were reporting not being able to make ends meet; managing basic food, health and educational needs was proving to be a struggle. This was true not only for the poorest, but for many middle-class people, too. Even lowincome households in the UK reported finding it hard to adequately feed small children.

In the developing countries as well as in the UK, there was support from within communities, as well as some valued government and faith-based support. In all of these contexts, including the $\mathrm{UK}$ with its welfare state (itself increasingly under threat), it was the most informal sources of support - help from neighbours, kin and family networks, credit from local shops - that people reported relying on most regularly and most successfully. Yet even then, and particularly in the 2009 developing country research, it seemed that the ties that bind communities together were at risk of unravelling, as social life and social action were on the decline, and crime rates are believed to have risen. The pressure on these informal social resources was proving to be too great in many places, and many people spoke of the depletion of community support resources, as people turned inwards, focusing on helping those nearest and on coping themselves.

Traditional institutions such as church and mosque organisations were also frequently cited as important and timely sources of support. While there were some concerns about the exclusionary nature of such institutions - in Nairobi, non-Muslims were critical about mosque assistance going to Muslims only, for instance - it seemed clear that these institutions were positioned and able to respond fast when needed (see Tadros, this IDS Bulletin).

One particularly important finding in relation to the new challenges to civil society is how few formal civil society organisations (CSOs) were found to be playing a significant role in supporting people in coping with the strains of these shocks (see Goldenberg, this IDS Bulletin). Development NGOs were criticised by a number of people for not helping when they were most needed, and some were even being forced to scale back as their own funding was cut. Microfinance providers were 
criticised in Bangladesh for creating intolerable debt burdens on poor people. As the research was small in scale, these findings cannot be taken as representative; yet they point to the limitations of aid-funded NGOs, in responding to shocks of this nature. Formal CSOs played a more prominent role in the UK than in the developing countries, often as alternative or contracted-out service providers.

In the developing countries, some government programmes were working well. Yet coverage was typically inadequate, and other schemes were not reaching the poorest. Familiar problems with social protection schemes were confirmed by analyses of what was working on the ground, including widely reported errors of inclusion and exclusion. The informal sector 'cushioned' much of the blow of the crises, absorbing many poor and vulnerable people, including poor women, into low-paid work at this time. This highlights the gap in social protection for informal sector workers as a critical policy concern. The importance of effective state social protection provision in developing countries was highlighted by the evidence of the safety net provided by the welfare state in the UK. While there was considerable hardship and stress for these lowincome UK communities, unlike some of their developing country counterparts, job losses and rising costs of living did not throw people in the UK communities into sudden and extreme forms of destitution and desperation. This marked difference in people's experiences of social protection testifies to the effectiveness of the welfare state (in the period before the cuts took effect, in early 2010): it is clear that with its automatic provision, universal rights of access to income protection and social services, and overall stabilising and insurance effect, the welfare state was greatly more effective than the patchwork of social schemes in place, even in those developing countries with relatively strong social protection systems (such as Jamaica and Indonesia). Whether this safety net effect will remain in place after the period of fiscal cuts targeting welfare spending, introduced by the Coalition government from 2010, remains to be seen.

\subsection{Awareness of the global}

A final finding worth noting because of the implications for civil society, is that research found that many people, even those who had been very directly and in some cases seriously affected by the global economic turbulence, seemed unaware of the global sources of the problems they faced. Many people seemed to find global connections to their concerns unfamiliar or believe them to be too complex or beyond their capacity to understand. For others, there was a sense that while problems might be global in their origin, it was at the national or local levels that there was some potential for agency, for their leaders or officials to be able to act, and on which they could themselves aspire to have any influence.

\section{Conclusions: the implications and challenges for civil society}

These findings are in-line with the view of the new global risk context as one of complex, compound shocks that are not limited to a single sector or issue, and are fast-moving and diverse in their impacts. The first challenge for civil society in this context is that it renders sectoral or single-issue specialisms less relevant: the nature of the shocks differs greatly according to country context, and to the interaction of climate, political and more localised conditions, with the global economic shocks emanating from commodity price volatility and financial crises. It seems likely that a robust civil society response to future global shocks will require a coordination of actors across different areas of expertise and with wide-ranging regional, organisational and advocacy capacities, similar to emergency response work, but on a more global and multi-level scale.

A second and related challenge is that the complex and compound nature of these shocks undermines efforts to monitor and track impacts, and therefore to engage in successful policy advocacy on tackling the poverty impacts of these shocks. To date, efforts to highlight the impacts on people living in poverty have not had an important or noticeable impact on aid and global governance decision-making around crisis response. Efforts to assess the social impact, including that by IDS, have been minuscule in coverage (and therefore weakly credible), as well as typically de-linked from the important policy spaces. By contrast, the case for direct support to big business interests has been highly successful, crowding out considerations of direct support to small businesses or the informal sector, let alone to social protection measures that might support consumer demand directly. 
Yet, civil society organisations with their networks of partners on the ground, across local and global contexts, and with lobbying capacities in policy spaces are also uniquely well-positioned to monitor and track the impacts of these crises. Their advantages and capacities in this area include:

- Speed and trust: pre-existing relationships in communities enable rapid, participatory research in fast-changing contexts;

- Capacity to build on existing knowledge: preexisting knowledge of local conditions that enable understanding of impact and attribution of cause and likely effect;

- Coverage and reach: networks across local-global divides enable local experiences to be transmitted to global audiences;

- Credibility: evidence generated by the large NGOs with established brands and wide public recognition are likely to enjoy credibility with both the public and policymakers.

A new opportunity for civil society engagement in monitoring crises exists in the form of the new platform, UN Global Pulse (see McGregor, this IDS Bulletin)..$^{5}$ This seeks to deploy new technologies and global partnerships to provide fast global monitoring coverage of crisis impacts and vulnerabilities, in this context of rising global risks.

The third challenge for civil society is the level of crisis response. The NGO response at the local level to the recent crises, has evidently been hit hard by the fact that, as the recent survey of 640 CiSOs found, many have themselves been hit hard by funding cuts, and have had to scale down activities, lose staff and engage in new fundraising activities, with the problem apparently most severe for CSOs in African countries (Hanfstaengl 2010). Dependence on voluntary contributions and aid flows look ever more precarious in the context of global downturn, signalling the (perennial) need for more sustainable sources of financing.

Part of this challenge is that the policy level that now matters is above nation-states, with the growing mismatch between global problems and the sites in which they are to be addressed, giving rise to the crises of efficiency, legitimacy, identity and equity identified by Castells (2008). The G20 has come to the fore, primarily as a result of the recent shocks. It is to date, substantially without consultative or participative function, and decision-making appears to be opaque, yet $a d h o c$. The emergence of the G20 could be seen as an opportunity for civil society engagement in that it is clearly the highest level of global governance at which global shocks are being managed. At the same time, the widening of the G8 membership to include large middle-income or developing countries may offer openings for national civil society groupings in some of the BRIC countries.

What will civil society say once it successfully negotiates entry into this new global public sphere? It is not clear what new ideas have emerged for fairer and more sustainable ways of managing the global economy to work better for people. The present moment represents an opportunity to raise alternatives, but this space has yet to be filled with powerful new understandings of global economy. By contrast, a number of arguments familiar from the so-called Washington Consensus have gained - or regained - authority in the recovery period. The best example is the view that the recent economic resilience of developing countries owed to their previous fiscal prudence.

A period of fiscal consolidation is now beginning across the rich world, the burden of which - it seems a safe bet - will be borne by poorer people and women, and not only within those developed countries. With the era of the spending state over, at least for now, the space for civil society to intervene to influence public spending in favour of powerless and vulnerable groups seems to be narrowing. Where, then, should debates meaningfully focus? There are many issues about which entirely fresh thinking seems warranted. Some issues this author would like and hope to see global civil society take up at this time, would include reconsideration of the moral limits to economic globalisation in a context of persistent failures to govern the global economy, with specific attention to food commodity speculation and the regulation and taxation of global financial flows; serious reconsideration, too, to the hidden costs of so-called resilience to economic crises, and in particular the roles of women in meeting these through their unpaid care work; and finally, proper attention to the meanings and implications of the wave of social unrest and discontent unfolding across the world in 2011. 


\section{Notes}

* The idea for this article came from John Gaventa, and it was written on the basis of a series of discussions we have had since 2009. Many thanks are due to Heather Mackenzie and FIM (Forum for Democratic Global Governance) for supporting the preparation and presentation of this article at CIVICUS. The article also draws on research into the poverty impacts of the Triple F crisis funded by the UK Department for International Development (DFID), the Joseph Rowntree Foundation and Oxfam GB. The author acknowledges the role of the research partners involved, but all interpretations here are hers alone.

1 CIVICUS is a global network of civil society organisations, headquartered in South Africa. It produces the Global Civil Society Index and organises the annual World Assembly. For a summary of the discussion, see www.civicus.org/what-we-do/cross-cuttingprojects/world-assembly/2010-world-assembly; www.ids.ac.uk/go/news/is-civil-societyequipped-to-face-multiple-linked-global-crises/.

2 In its most recent review of the Millennium Development Goals, for example, the World

\section{References}

Castells, M. (2008) 'The New Public Sphere: Global Civil Society, Communication Networks, and Global Governance', The ANNALS of the American Academy of Political and Social Science 616: 78

Evans, A.; Jones, B. and Steven, D. (2010) Confronting the Long Crisis of Globalization, Ontario: Brookings/CIC

Global Pulse (2010) Voices of the Vulnerable: Recovery from the Ground Up, New York: United Nations Secretary General's Office/Global Pulse, www.unglobalpulse.org/sites/all/files/reports/ Voices-of-the-Vulnerable.pdf (accessed 28 July 2011)

Hanfstaengl, E-M. (2010) Impact of the Global Economic Crises on Civil Society Organizations, New York: NGO Committee for Social Development, http://ngosocdev.wordpress.com/2010/01/28/174 (accessed 28 July 2011)

Hossain, N. et al. (2009) 'Accounts of Crisis: Poor People's Experiences of the Food, Fuel and Financial Crises in Five Countries', mimeo, Brighton: IDS

Hossain, N. and Green, D. (2011) Living on a Spike: How is the 2011 Food Price Crisis Affecting
Bank (2010) concludes that it was precisely macroeconomic 'prudence' and economic openness that enabled many developing countries to weather the global storm so effectively.

3 See, e.g. The Economist, 'Emerging Markets and Recession', 30 December 2009.

4 The research is reported in Hossain et al. (2009, 2010, 2011) and Hossain and Green (2011) (www.ids.ac.uk/go/idsproject/the-socialimpacts-of-crisis; www.ids.ac.uk/go/idsproject/ the-impacts-of-the-global-economic-downturnon-communities-and-poverty-in-the-uk).

Partners included BRAC Development Institute in Bangladesh, SMERU in Indonesia, researchers from Mpereeza Associates in Kenya and Givil Society for Poverty Reduction in Zambia, from the Universities of Manchester and Sussex and the Rural Community Network in Northern Ireland. IDS colleagues, Joy Moncrieffe and Mariz Tadros, led the research teams in Jamaica and Yemen, respectively.

5 Global Pulse is an initiative out of the United Nations' Secretary General's office to facilitate global monitoring of crisis impacts (www.globalpulse.org).

Poor People?, Oxfam Research Reports, Oxford: Oxfam/IDS

Hossain, N.; Fillaili, R.; Lubaale, G.; Mulumbi, M. and Rashid, M. (2010) 'Social Impacts of Crisis: Findings from Community-level Research in Five Developing Countries', mimeo, Brighton: IDS

Hossain, N.; Byrne, B.; Campbell, A.; Harrison, E.; McKinley, B. and Shah, P. (2011) The Impact of the Global Economic Downturn on Communities and Poverty in the UK, York: Joseph Rowntree Foundation

McCord, A. (2010) 'The Impact of the Global Financial Crisis on Social Protection in Developing Countries', International Social Security Review 63: 31-45

Scholte, J.A. (2010) 'Global Governance and UK Poverty', mimeo, London: Joseph Rowntree Foundation

Tiwari, S. and Zaman, H. (2010) The Impact of Economic Shocks on Global Undernourishment, World Bank Policy Research Working Paper 5215, Washington DC: World Bank

World Bank (2010) Global Monitoring Report 2010: The MDGs after the Crisis, Washington DC: World Bank 